Article

\title{
Potential Application of Fluorescence Imaging for Assessing Fecal Contamination of Soil and Compost Maturity
}

\author{
Hyunjeong Cho ${ }^{1,2}$, Hoonsoo Lee ${ }^{2}$, Sungyoun Kim ${ }^{1}$, Dongho Kim ${ }^{1}$, Alan M. Lefcourt ${ }^{2}$, \\ Diane E. Chan ${ }^{2}$, Soo Hyun Chung ${ }^{3, *}$ and Moon S. Kim ${ }^{2, *}$ \\ 1 Experiment and Research Institute, National Agricultural Products Quality Management Service, 141, \\ Younjeon-ro, Gimcheon-si, Gyeongsangbuk-do 39660, Korea; hjcho201@gmail.com (H.C.); \\ youn5326@korea.kr (S.K.); anoldmu@korea.kr (D.K.) \\ 2 Environmental Microbial and Food Safety Laboratory, Beltsville Agricultural Research Center, \\ Agricultural Research Service, USDA, 10300 Baltimore Avenue, Beltsville, MD 20705, USA; \\ hoonsoo.lee83@gmial.com (H.L.); alan.lefcourt@ars.usda.gov (A.M.L.); diane.chan@ars.usda.gov (D.E.C.) \\ 3 School of Biosystem and Biomedical Science, College of Health Science, Korea University, B-dong 551, \\ Hana-Science Building, 145 Anam-ro, Seongbuk-gu, Seoul 02841, Korea \\ * Correspondence: chungs59@korea.ac.kr (S.H.C.); moon.kim@ars.usda.gov (M.S.K.); \\ Tel.: +82-2-3290-5641 (S.H.C.); +1-301-504-8462 (M.S.K.)
}

Academic Editor: Kuanglin Kevin Chao

Received: 19 May 2016; Accepted: 24 August 2016; Published: 27 August 2016

\begin{abstract}
Pathogenic microorganisms can lead to serious outbreaks of foodborne illnesses, particularly if fresh produce becomes contaminated and then happens to be inappropriately handled in a manner that can incubate pathogens. Pathogenic microbial contamination of produce can occur through a variety of pathways, such as from the excrement of domesticated and wild animals, biological soil amendment, agricultural water, worker health and hygiene, and field tools used during growth and harvest. The use of mature manure compost and preventative control of fecal contamination from wildlife and livestock are subject to safety standards to minimize the risk of foodborne illness associated with produce. However, in a field production environment, neither traces of animal feces nor the degree of maturity of manure compost can be identified by the naked eye. In this study, we investigated hyperspectral fluorescence imaging techniques to characterize fecal samples from bovine, swine, poultry, and sheep species, and to determine feasibilities for both detecting the presence of animal feces as well as identifying the species origin of the feces in mixtures of soil and feces. In addition, the imaging techniques were evaluated for assessing the maturity of manure compost. The animal feces exhibited dynamic and unique fluorescence emission features that allowed for the detection of the presence of feces and showed that identification of the species origin of fecal matter present in soil-feces mixtures is feasible. Furthermore, the results indicate that using simple single-band fluorescence imaging at the fluorescence emission maximum for animal feces, simpler than full-spectrum hyperspectral fluorescence imaging, can be used to assess the maturity of manure compost.
\end{abstract}

Keywords: fresh produce; pathogenic microorganism; compost; feces; hyperspectral fluorescence imaging

\section{Introduction}

From 1996 to 2010, approximately 131 fresh produce-related outbreaks occurred, resulting in 14,132 outbreak-related illnesses, 1360 hospitalizations and 27 deaths [1,2]. The increase in cases of foodborne illness linked to fresh produce can be attributed not only to increased consumption, 
but also to the increased popularity of processed ready-to-use products, centralized production operations, and more effective surveillance of illness incidents [3,4]. According to investigations of pathogenic microbial outbreaks that have occurred in the United States, pathogens that were the leading causes of foodborne illnesses, hospitalizations, and deaths have been Norovirus, Salmonella, Clostridium perfringens, Campylobacter spp., Listeria monocytogenes, and E. coli (STEC) O157 [5].

Fresh produce can become contaminated with pathogens during growth, harvesting, packaging, or food preparation through various routes, such as manure compost being used as a soil amendment for soil quality, irrigation water, or fecal contamination by active wildlife or proximity to livestock in the field [6-9]. Data on the source of outbreaks shows that the majority of outbreaks related to fresh produce have mostly been caused by zoonotic bacterial pathogens of animal origin such as Salmonella and E. coli O157:H7 [2]. Three surveys related to distribution of Salmonella and pathogenic E. coli shows that they have been commonly isolated from feces of beef and dairy cattle, and over $13 \%$ of cattle harbor either E. coli O157:H7 or Salmonella [10,11]. Similarly, two surveys found that between 13\% and $23 \%$ of feral swine tested positive for the same two pathogens, and feral swine was reported to be the animal showing the second highest incidence of carrying pathogenic E. coli [12], with beef cattle showing the highest incidence. Thus, it shows that the intrusion of wild or domestic animals into production fields or the contamination of animal feces through various routes are consistent with outbreaks related to produce.

As another source of fecal contamination, manure compost is organic material that has been degraded into a nutrient-stabilized, humus-like substance through microbial activity that generates sufficiently high thermophilic temperatures $\left(\geq 55^{\circ} \mathrm{C}\right)$ to kill enteric bacterial pathogens originally present in the feedstocks [13]. However, even if finished compost is properly maintained, it can become recontaminated from environmental sources, such as wild terrestrial animals and birds, so pathogens such as Salmonella spp. and E. coli can regrow in finished compost or inadequately composted manure [14-16]. Therefore, detecting the fecal presence in soil or compost would improve efforts to ensure adequate maturation of composts at all stages of the composting process as well as to avoid harvesting in contaminated field areas.

Microbial standards for the biological amendments of animal origin such as manure compost provide the biological criteria for applying biological amendments to the field to ensure the safety of produce [17]. These analytical methods for microbial standards, being mostly conventional detection methods relying on cultivation, are time-consuming and material- and labor-intensive [18]. In general, microbial contamination tends to occur in a limited and randomized manner. Thus, before conducting a regulated traditional method, a more effective and rapid on-site method for screening contaminated samples has been requested over the past years [19].

Optical sensing techniques including hyperspectral imaging (HSI), as research tools, have gained increasing attention as tools for the rapid detection of anomalies in food products in recent years [20-24]. Hyperspectral imaging, which combines imaging and spectroscopic technology, can rapidly acquire spectral information at each pixel in an image in a non-invasive and non-destructive manner, and thus has the potential for use in screening products for contaminants based on unique spectral features across the sample image [25]. Originally, hyperspectral imaging was developed for remote sensing applications, but it has now been applied in a number of fields including food safety and quality, pharmaceuticals and material science [26].

In particular, regarding the detection of animal feces, the investigation of optimal fluorescence excitation and emission bands found that fluorescence emissions with excitation at 410 to $420 \mathrm{~nm}$ from naturally occurring chlorophyll $a$ and its metabolites were good markers for fecal contamination [27]. Moreover, hyperspectral fluorescence imaging has been applied to detect bovine fecal contamination on produce for biological safety, and various methods of image processing, spectral pretreatment, and modeling have been developed and refined to improve resolution and lower detection limits. For example, hyperspectral fluorescence imaging showed great potential for detecting cow fecal contamination spots on apples [28-30], cantaloupes [31] and tomatoes [32] and was found to be 
more sensitive than reflectance imaging. Moreover, recent studies include hyperspectral fluorescence imaging on green leaves with high concentrations of chlorophyll $a$, such as romaine lettuce and baby spinach, and a two-band ratio method was determined for distinguishing fecal contamination spots on leafy greens because the emission peaks from bovine fecal matter (near $670 \mathrm{~nm}$ ) and green plant leaves (near $685 \mathrm{~nm}$ ) occur in close proximity to the same visible spectral region [33-35]. This rapid screening method using fluorescence imaging can potentially be used in situ to detect fecal matter in soils and manure compost samples and to enhance the efficacies of soil and compost sampling operations.

In this research, hyperspectral fluorescence imaging techniques were investigated (1) to characterize feces samples from bovine, swine, poultry, and sheep species; and (2) to determine feasibilities for detecting and identifying the presence of animal feces and the species origin of the feces, respectively, on or in soil-feces mixtures. In addition, the imaging technique was evaluated for the potential determination of manure compost maturity. The aim of this investigation was to develop field portable imaging devices for in situ screening of soil and compost samples for animal fecal matter. Ultimately, such devices will greatly enhance the efficacies and economics of the current sampling regimes for microbial testing.

\section{Materials and Methods}

\subsection{Sample Preparation}

Fresh samples of animal feces from dairy cows, pigs, chickens, and sheep were collected from animal research facilities and farms at the Beltsville Agricultural Research Center (BARC), Agricultural Research Service, United States Department of Agriculture. All fecal samples consisted of fresh droppings, and for each species, four samples of about 40 to $80 \mathrm{~g}$ each from individual animals were collected into polypropylene containers of $100 \mathrm{~mL}$ using sterilized disposable spatulas. The feces of dairy cows, chicken, and pigs were collected from individually housed animals, while very fresh sheep droppings were collected from free-ranging animals (outdoors). Collected samples are immediately stored at $-20{ }^{\circ} \mathrm{C}$, and later allowed to stand at least $30 \mathrm{~min}$ to acclimate to room temperature before being used for imaging. Amended soil (sandy loam) samples were obtained from BARC high tunnel facilities usually used to grow produce. First, the fecal samples from each animal species and the soil samples were placed on a non-fluorescent tray, with each sample weighing approximately $30-35 \mathrm{~g}$ and covering an area approximately $5 \mathrm{~cm}$ in diameter. Hyperspectral fluorescence line-scan images of the feces and soil samples were replicated four times. Second, to evaluate soil-feces mixture matrix, soil samples were placed into four Petri dishes: one contained only soil, two contained soil topped with aggregated feces particles (approximately 5 to $10 \mathrm{~mm}$ in size) from each of the four animal species, and one contained soil mixed randomly with finely-cut feces particles (less than $3 \mathrm{~mm}$ in size) from each of the four animal species. All four Petri dishes were scanned together in one pass for hyperspectral image acquisition/analysis, replicated four times.

In addition, samples of animal-manure-based compost aged for one, two, three, and four months were obtained from the BARC Composting Research Facility on 11 February 2016. The exposed outdoor compost piles had been created on 7 January 2016 (one month prior), 2 December 2015 (two months prior), 7 November 2015 (three months prior), and 7 October 2015 (four months prior), placed over bare earth in windrows approximately $50 \mathrm{~m}$ long, $1.5 \mathrm{~m}$ wide, and $1 \mathrm{~m}$ high. In terms of species origin of the animal feces present, the compost was mainly derived from cow feces along with mixtures of feces from other animal species such as horse, pig, sheep, and chicken. Note that compost contains mixtures of landscape trimmings and animal feed/bedding materials as well as feces/manure, and that the exact makeup and quantity of animal-fecal species were not quantified in this investigation. From each aged compost windrow, approximately $3 \mathrm{~kg}$ of compost was shoveled out to one mixing bucket from each of five holes distributed along the length of the $50 \mathrm{~m}$ windrow, for a total of $15 \mathrm{~kg}$ to mix together to produce a representative batch of the aged compost. Immediately after the mixing, approximately $3 \mathrm{~kg}$ of each representative compost batch was placed into a plastic 
bag for storage at $-20^{\circ} \mathrm{C}$. The four bags of aged compost were allowed to stand at room temperature for at least $30 \mathrm{~min}$ before being used for the imaging study. Each of the four batches of aged composts was used to fill five individual Petri dishes, for an arrangement of 20 samples in Petri dishes (four aged compost batches, five dishes per batch) that were then scanned together in one pass for hyperspectral imaging. Images were acquired for a total of 80 compost samples in four sets of 20 Petri dishes (in 4 aged month $\times 5$ sample arrangement).

\subsection{Hyperspectral Imaging System}

A line-scan (push-broom) hyperspectral imaging (HSI) system and LED-based violet fluorescence excitation light were used in this study. The HSI system consists of a 14-bit electron-multiplying charge-coupled-device (EMCCD) camera (MegaLuca R EMCCD camera, Andor Technology PLC, Belfast, Northern Ireland), an imaging spectrograph (Hyperspec VS imaging spectrograph, Headwall Photonics, Fitchburg, MA, USA) with $60 \mu \mathrm{m}$ slit, a lens (Schneider-Xenoplan 1.4/23 C-mount lens, Schneider Optics, Hauppauge, NY, USA) and a motorized positioning table (Velmex, Bloomfield, NY, USA). Figure 1 shows a schematic illustration and a photo of the HSI system which can acquire visible or near-infrared reflectance images by using quartz-tungsten halogen lights as well as fluorescence images by using either ultraviolet (UV) or violet (V) excitation lights. The two UV/violet LED-based line lights were built in-house and each incorporated four $365 \mathrm{~nm}$ and four $405 \mathrm{~nm} 10 \mathrm{~W}$ light-emitting diodes (LEDs; LedEngin, CA, USA). A $480 \mathrm{~nm}$ long wavelength pass filter (Kodak Wratten Gelatin Filter, No. 8) was placed in front of the object lens to remove the tail-end of the excitation light and second-order effect. In this study, the HSI system was used only with the $405 \mathrm{~nm}$ violet excitation light because previous research found that fluorescence from the violet excitation (e.g., $410 \mathrm{~nm}$ ) enhanced the detection of fecal matter on produce to a greater degree when compared to fluorescence from UV excitation or visible/near-infrared reflectance [33].

Total 81 layers of hyperspectral images were collected across the range of 480 to $800 \mathrm{~nm}$ at approximately $4 \mathrm{~nm}$ intervals. The EMCCD has $1004 \times 1002$ pixels (spatial $\times$ spectral), which include spectral bands below and above the 480 to $800 \mathrm{~nm}$ spectral region of interest. Of the 1002 spectral pixels, only the 405 pixels within the spectral region of interest were acquired. In addition, pixel binning (averaging) was used to reduce the data volume by two horizontally and by five vertically, resulting in 502 spatial pixels and 81 spectral wavebands. Hyperspectral images were acquired using line-scan incremental steps of $1 \mathrm{~mm}$ with $0.09 \mathrm{~s}$ exposure time for pure fecal, soil-fecal matrix, and compost samples.
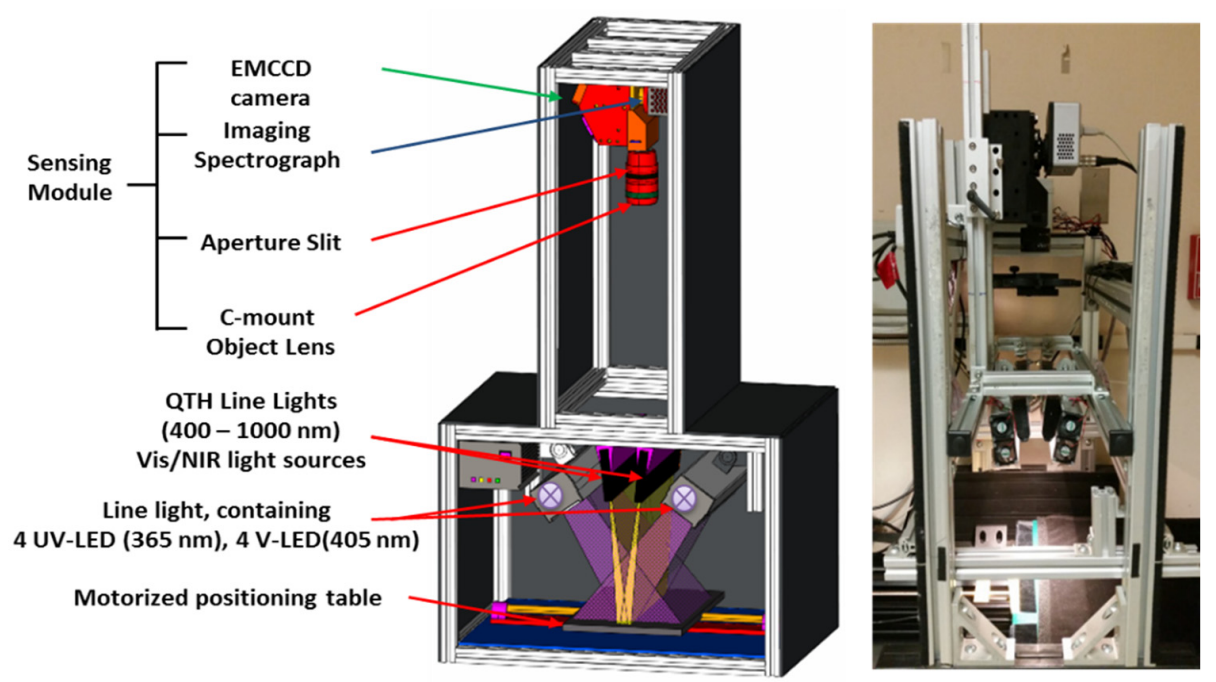

Figure 1. Schematic illustration and color photo of hyperspectral imaging (HSI) system. Only the violet (405 nm) LEDs were used as excitation source for fluorescence imaging application in the current study. 
HSI system data acquisition was carried out using software developed in-house in Visual Basic (Version 6, Microsoft, Seattle, WA, USA). Sample images were corrected with subtraction of EMCCD dark current and adjustment for spatial flat-field responses using two additionally acquired images, respectively. A dark current image was acquired with the light source turned off and the camera lens covered. A flat-field image of a uniform fluorescent target sample (i.e., white plotter paper) was used to correct for heterogeneous illumination and responses of the HSI system. Image processing and analyses, such as dark current and flat-field corrections, spectral data extraction, and principal component analysis (PCA), were accomplished with combined use of in-house software written in Visual Basic and Matlab (Version R2007b, The MathWorks, Inc., Natick, MA, USA, 2007).

\section{Results and Discussion}

\subsection{Fluorescence Characteristics of Animal Feces and Soil}

Figure 2a shows a color photo of representative animal fecal and soil samples as arranged for the imaging study for comparison with each other; Figure $2 \mathrm{~b}$ shows the mean sample spectra extracted from a nine-pixel $(3 \times 3$ pixels $)$ region of interest within the area of each sample type in the hyperspectral images that illustrate the dynamic fluorescence emission characteristics of fecal materials. The most common fluorescence characteristic of the fecal materials was an emission maximum in the red region of the spectrum at about $676 \mathrm{~nm}$, with a secondary peak at about $720 \mathrm{~nm}$, especially for cow and sheep feces. Pig and chicken feces exhibited a relatively strong emission in the green region with an emission maximum at approximately $520 \mathrm{~nm}$. In addition, emission peaks were observed in the pig and chicken spectra near $635 \mathrm{~nm}$, where a more pronounced emission peak can be seen in the chicken spectrum [27]. The emission features of pig, cow, and chicken feces obtained from the HSI system using $405 \mathrm{~nm}$ excitation were consistent with previously reported results from a spectrofluorometer. Fluorescence spectral features of sheep feces were nearly the same as those for cow feces with a minimal emission in the green region and dominant emissions in the red region at $676 \mathrm{~nm}$ and $720 \mathrm{~nm}$. Figure $2 \mathrm{~b}$ also shows a representative soil spectrum that exhibits minimal fluorescence emissions through the green and red regions.

Chlorophyll $a$ molecules are present in green plants and emit unique fluorescence features in the red and far-red regions of the spectrum, with emission peaks at 685 and $730 \mathrm{~nm}$ having been reported [36,37]. Using a fluorescence excitation maximum at around $410 \mathrm{~nm}$, strong fluorescence emissions were previously observed for the feces of cow, pig, chicken and sheep in the red region of the visible spectrum, with peaks near $676 \mathrm{~nm}$. The red emissions observed in animal fecal matter are suggested to be chlorophyll $a$ or its metabolites such as pheophorbide $a$. The spectral change resulted from the green roughages consumed by the animals, and the blue-shifted spectral change was reported to occur with chlorophyll $a$ having passed through the digestive tract of animals [27]. For chicken feces, the $635 \mathrm{~nm}$ emission peak is thought to emanate from Protoporphine IX.

Figure 2c,d show hyperspectral images of the samples at $520 \mathrm{~nm}$ and $676 \mathrm{~nm}$, respectively. The $520 \mathrm{~nm}$ green-band image shows that the relative intensities of chicken feces followed by pig feces were significantly higher than those of sheep and cow feces. At $676 \mathrm{~nm}$, the chicken feces exhibited the highest fluorescence emissions compared to other fecal samples. Both cow and sheep feces exhibited some bright spots where the relative fluorescence intensities were similar to chicken feces. The $676 \mathrm{~nm}$ image demonstrates that the fecal matter can be potentially differentiated from soil. 


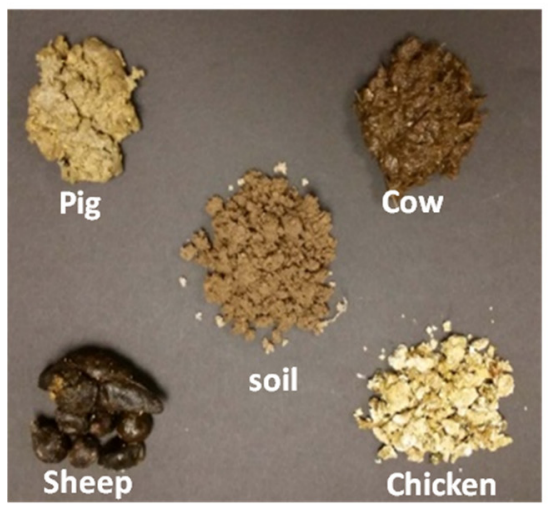

(a)

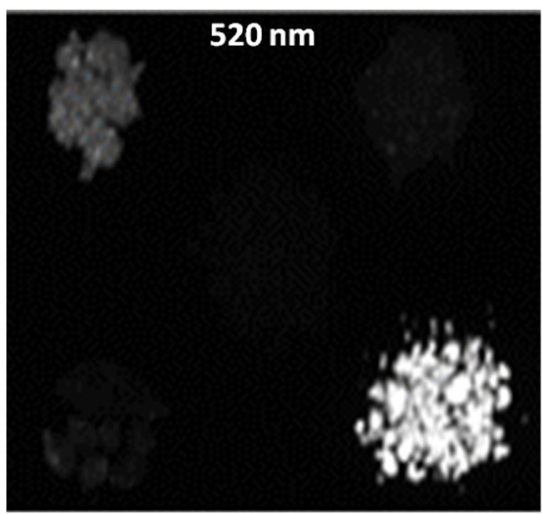

(c)

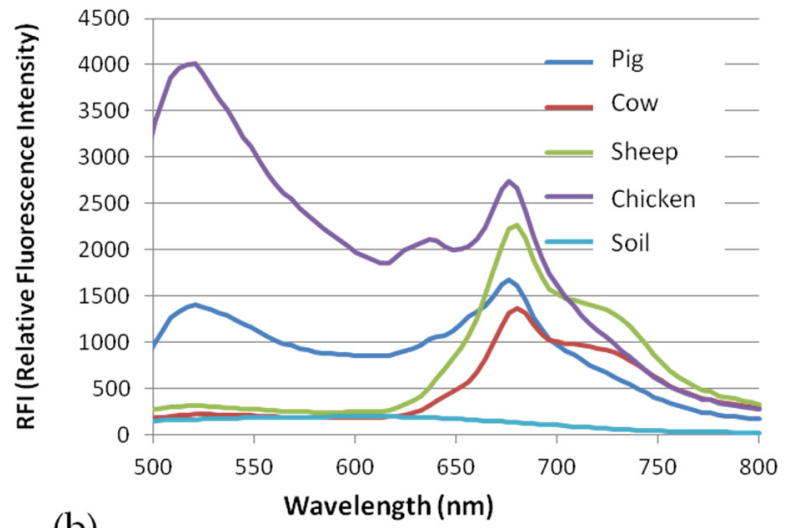

(b)

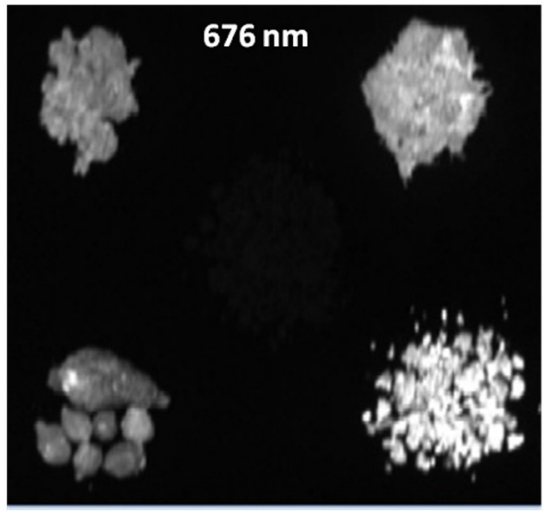

(d)

Figure 2. (a) Color photo of feces samples from four animal species and one soil sample; (b) Representative fluorescence spectra of animal fecal and soil samples. Hyperspectral fluorescence images of the samples acquired at (c) $520 \mathrm{~nm}$ and (d) $676 \mathrm{~nm}$.

\subsection{Discrimination of Fecal Matter on Soil and in Mixtures with Soil}

Pathogenic microbial contamination of agricultural products by feces may occur in fields during planting, growing, or harvesting as a result of wildlife intrusion, immature compost used as an amendment for soil quality, or irrigation water contaminated by feces of either wildlife or livestock.

To explore the potential identification of the species origin of animal feces, the hyperspectral images of animal feces and soil samples shown in Figure 3 were subjected to PCA. The sample materials exhibited dynamic fluorescence characteristics, and PCA can reduce high spectral dimensions into a few significant principal components. The results showed that the first five principal components accounted for $99.8 \%$ of the spectral variation found in the samples. Figure 3a shows, from top to bottom, the first to fourth principal component (PC) score images. Note that the other PC score images were omitted for brevity. The first PC score image exhibited the relatively high emission features of the chicken feces followed by pig feces throughout the wavelength region under investigation. The second PC to fourth PC images highlighted differences between the individual feces samples.

Figure $3 \mathrm{~b}$ illustrates the distributions of individual feces and soil pixels in a scatter plot of the PC1, PC2 and PC 3 domains. Chicken feces pixels were the most scattered, yet are clearly separated from other samples. Soil with minimal fluorescence emission intensities exhibited the least scattered grouping. The pixels for cow and sheep feces were districted in a close proximity in the PC1 to PC3 domain, as suggested by the spectral similarity observed in Figure $2 b$. Figure $3 c$ is an RGB-composite image created using PC2, PC3, and PC4 score images (in Figure 3a). Individual feces samples exhibited unique color schemes suggesting that the identification of animal-fecal species in an animal feces-soil matrix may be possible using hyperspectral fluorescence imaging techniques. 
(a)
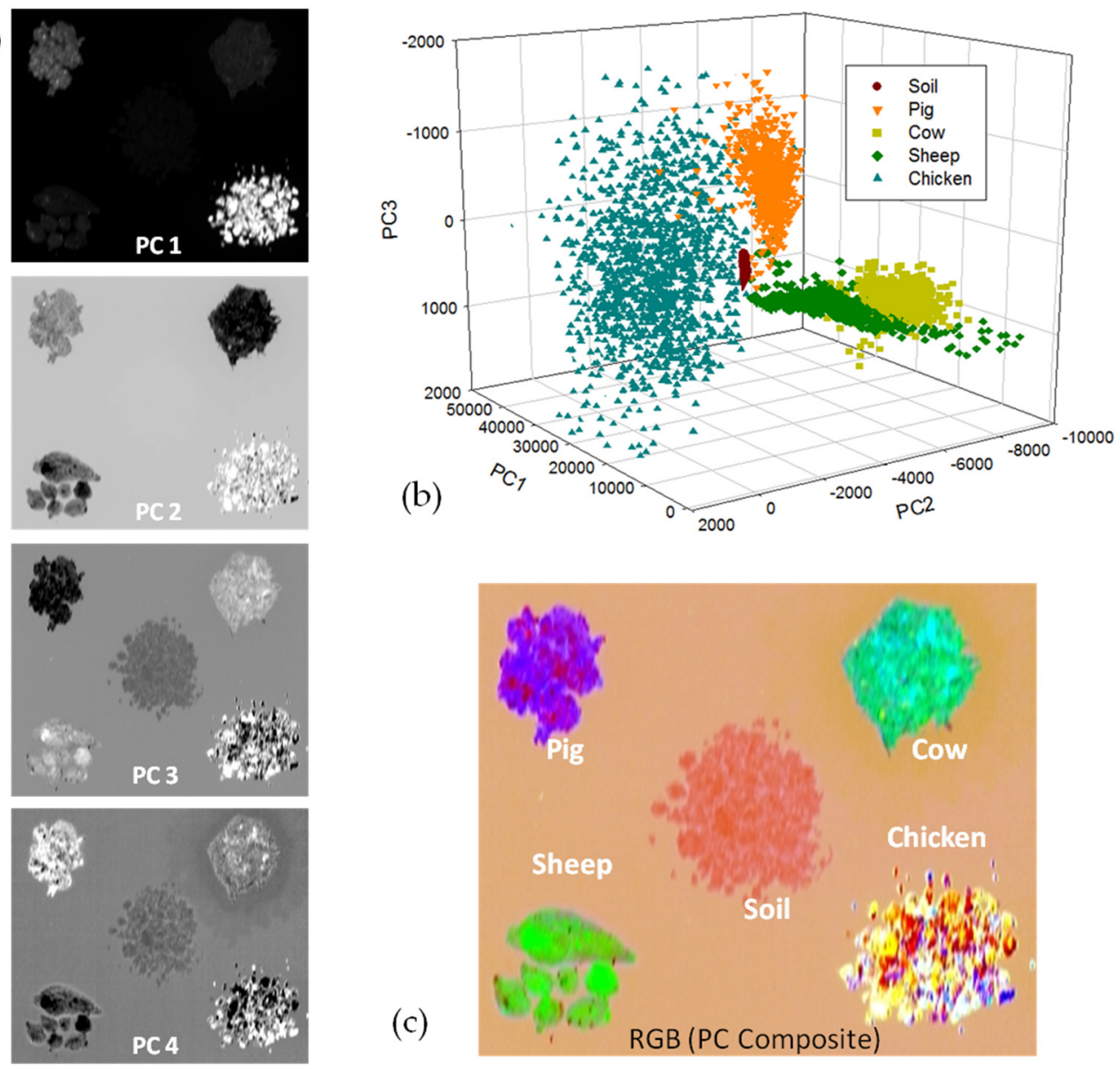

Figure 3. (a) First to fourth principal component (PC) score images of animal feces and soil samples; (b) Scatter plot of individual feces and soil samples pixels in PC1, PC2, and PC3 domains; (c) RGB color composite image obtained from a combination of PC2, PC3, and PC4 score images.

As shown in the color photo in Figure 4a, small feces particles present on top of or mixed in with soil cannot be easily distinguished by the naked eye, except sometimes for chicken feces particles because they tend to be much lighter in color compared to the adjacent soil particles. Figure $4 \mathrm{~b}$ shows a hyperspectral image at $676 \mathrm{~nm}$ (animal fecal peak wavelength). In this image, spatial placement of the fecal samples on or mixed in the soils can be seen clearly due relatively high fecal emission characteristics. On the basis of a single animal fecal emission band, a qualitative assessment of fecal presence is feasible - an automated threshold of the $676 \mathrm{~nm}$ image allows the detection of feces pieces in the samples (Figure 4c). Subjecting the hyperspectral images to PCA showed that the identification of individual animal-fecal species is also feasible in a soil-feces matrix, as illustrated in the RGB color composite image of the PC2, PC 3, and PC4 score images (Figure 4d). Individual PC score images were not shown for brevity. The upper-right Petri dish with the feces-soil mixture exhibited the four distinct color schemes of the feces for the four animal species. These results suggest that a simpler single-band imaging system can provide the detection of the presence of feces on or in soils, while a HSI technique is needed to determine the animal species of fecal materials. 


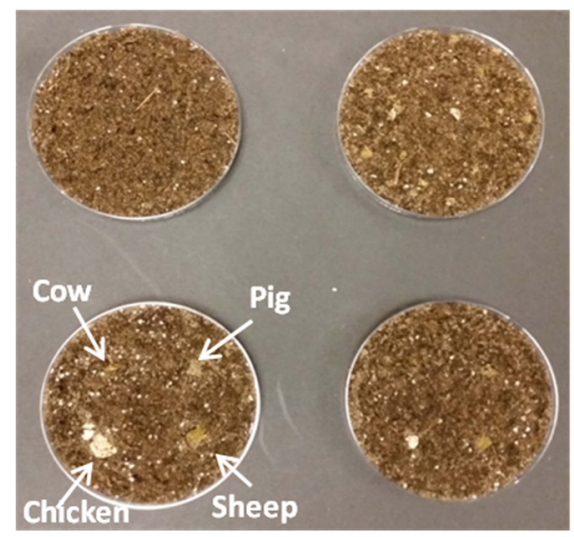

(a)

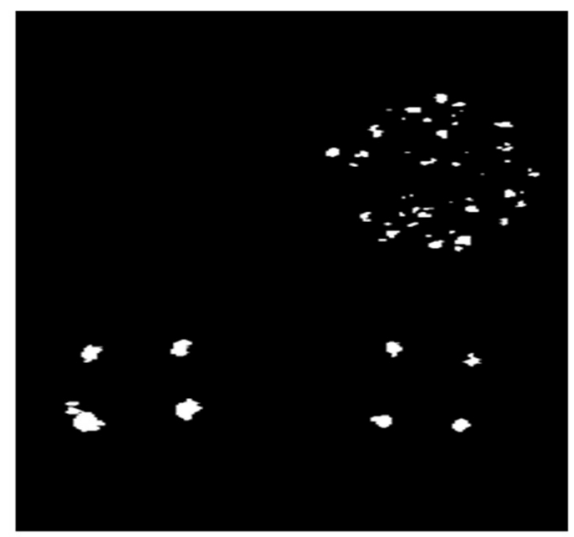

(c)

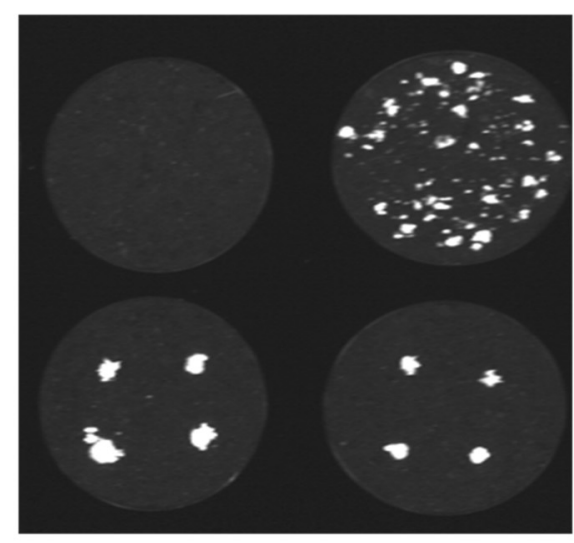

(b)

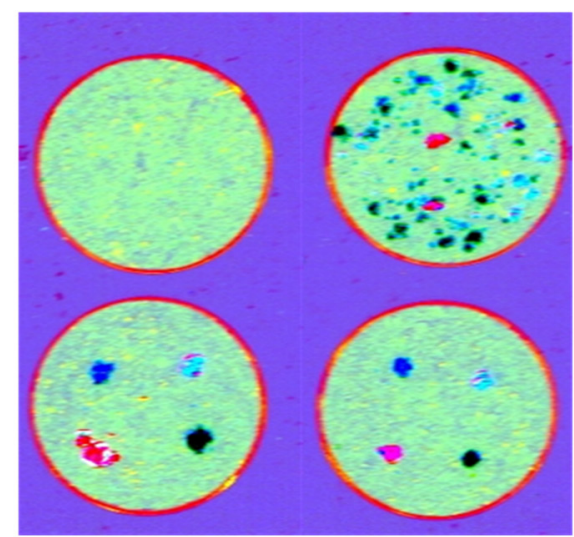

(d)

Figure 4. (a) Photo of representative feces-soil sample matrix where (in clockwise order from upper left) one Petri dish contains only soil, one Petri dish contains a random mixture of soil and fecal particulates from all animal species, and two Petri dishes (at bottom) each contain soil topped with larger fecal particulates from each of four animal species; (b) Fluorescence image of the representative soil-feces sample matrix acquired at $676 \mathrm{~nm}$; (c) Binary feces distribution image obtained by applying automated Otsu threshold (Otsu, 1979) to the $676 \mathrm{~nm}$ fluorescence image of soil-feces sample matrix; (d) RGB color composite image obtained from a combination of PC2, PC3, and PC4 score images of the soil-feces sample matrix.

\subsection{Identification of Fecal Presence as Related to Degree of Compost Fermentation}

In brief, mature compost is the result of a managed biological process that involves the microbiologically self-heated decomposition of organic residuals and byproducts such as animal feces, food/bedding materials, and landscape trimmings. Through this process, biosolids are stabilized, potential pathogens are reduced, and odors and insect attraction are eliminated [38,39]. Compost which is not adequately exposed to high temperatures for sufficient time periods may harbor some surviving bacterial pathogens, and these survivors may thrive and multiply under favorable conditions. Salmonella spp. has been reported to persist for 161 and up to 231 days in soils amended with contaminated composts where lettuce and parsley, respectively, were grown. The pathogens were detected on the plants for up to 63 days (lettuce) and 231 days (parsley) [6].

Figure 5a,b show a color photo and a $676 \mathrm{~nm}$ fluorescence image, respectively, for the representative compost samples obtained from compost windrows aged for one, two, three, and four months. The results show that (hyperspectral) fluorescence imaging was able to detect the fecal presence in the compost samples even though it was not identifiable by the naked eye. As shown in 
the F676 nm image, much fecal content was detectable in the one-month compost, but with the passing of time there was significant decomposition. However, the imaging results indicated that some trace fecal presence remained even after four months of composting. This observation was attributable to relatively slow composting rates during the cooler winter months, since all the compost samples were acquired from the outdoor facility in February 2015. Note that compost maturation depends on many factors including ambient temperature and environmental circumstances.

To further verify the change in fluorescence intensities based on aged compost samples, mean and standard deviation values for the fluorescence intensities at $676 \mathrm{~nm}$ were calculated. The total numbers of pixels acquired from 20 samples for each month were approximately 150,000. The results are plotted in Figure 5c. The average values of fluorescence intensities at $676 \mathrm{~nm}$ for the aged compost samples were $2040.2,914.3,803.7$, and 799.2, respectively. The fluorescence value between the one-month sample and the two-, three- and four-month samples showed a significant difference $(p<0.0001)$. However, statistically significant differences could not be confirmed between the two-, three- and four-month samples. Nevertheless, the mean and standard deviation of fluorescence intensities decreased with the aged months because the pixels with high fluorescence intensity $(676 \mathrm{~nm})$ were reduced. Therefore, these results suggest that the fluorescence value at $676 \mathrm{~nm}$ is related to the composting rates of manure.

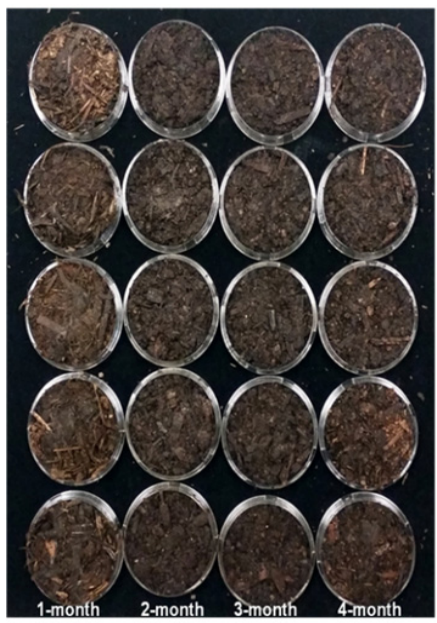

(a)

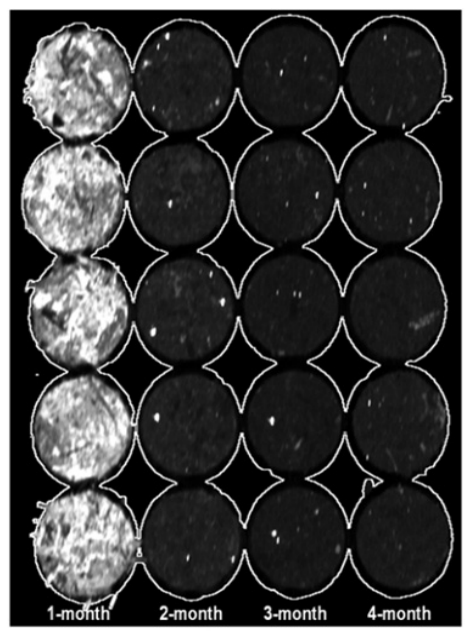

(b)

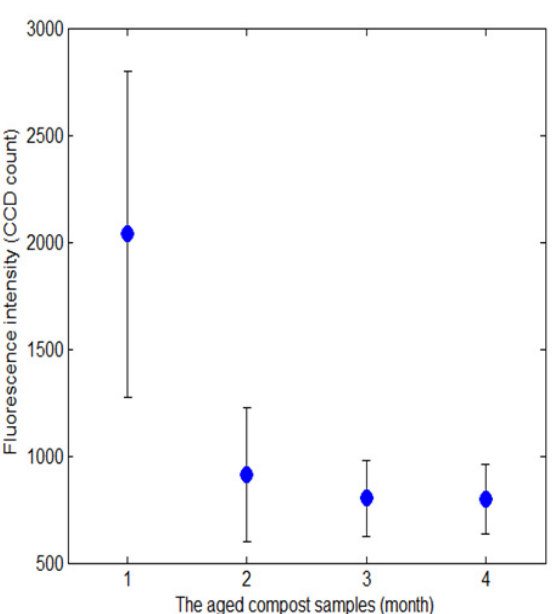

(c)

Figure 5. (a) Photo of aged compost samples; (b) Fluorescence image of the aged compost samples shown in the color photo acquired at $676 \mathrm{~nm}$. The presence of fecal matter (gray-white spots) is evident even after the two-, three-, and four-month composting for the compost samples under investigation. Note that the rest of the samples, sets 2 to 4 , exhibited similar responses and were omitted for brevity. The white boundary edges of the sample materials/Petri dishes were added to outline individual samples; (c) Mean and standard deviation values for fluorescence intensities at $676 \mathrm{~nm}$.

The U.S. Environmental Protection Agency, the U.S. Composting Council, and the FDA stipulate microbial criteria for finished compost to ensure biological safety when it is applied to the land, and the presence and amounts of fecal coliforms and Salmonella spp. must be confirmed as indicators of the total pathogen content $[17,40,41]$. Because making such determinations with current conventional methods is time-consuming and expensive, especially for small-scale farmers, there is a great need for new methods that can be used directly in-field and at lower cost to estimate whether compost is finished. The fluorescence imaging techniques demonstrated in this investigation may provide efficient and economical means to determine fecal presence at all stages of the composting process because fecal presence in the composting process means the process is under continuation or is not entirely finished. In the future, additional research for the relationship between the images of fecal spots at all stages of the composting process and the presence of microbial standards such as fecal coliforms or 
Salmonella spp. is planned to compare the results between the fluorescence imaging method and the conventional biological method.

\section{Conclusions}

In this study, a hyperspectral fluorescence imaging system developed in-house was used to characterize the unique spectral features of feces samples from dairy cows, pigs, chickens, and sheep. Furthermore, it was also demonstrated that the detection of animal feces and the identification of species origin in soil-feces mixtures are feasible. The results suggest that a simpler single-band imaging system can provide a means for the detection of the presence of feces on soils, while HSI imaging techniques are needed to determine the animal origin of fecal materials. In addition, single-band fluorescence imaging at $676 \mathrm{~nm}$ (feces emission maximum band) illustrated the detection of the presence of fecal matter in aged composts. Given the limited sampling of compost and animal fecal matter used in the present study, additional work to comprehensively test these methods will incorporate greater variety by sampling compost from different locations and production methods, and fecal material from a greater variety of animals whose environments, feeding regimes, and breeds differ in ways that may be typical for different animal production operations. However, the current results suggest that the methods presented in this investigation can be developed for the use of rapid in situ screening for animal feces in soil and compost samples where the presence or incomplete composting of fecal matter is a potential source of pathogenic microorganisms in agricultural fields.

Effective in-field fecal contaminant detection will help prevent the harvesting of produce considered to be contaminated due to in-field proximity with animal feces, and will also enable more precise and effective field sampling for off-site microbial pathogen detection tests. The development of field portable imaging devices for in situ screening of soil and compost samples for animal fecal matter is in progress. Ultimately, such devices will greatly enhance the efficacies and economics of the current sampling regimes for microbial testing. Further research will help optimize the use of image-based fecal detection methods to complement and support conventional microbiological testing methods.

Acknowledgments: The authors would like to thank Patricia D. Miller and Mónica Santín-Durán of Environmental Microbial and Food safety Lab, Beltsville Agricultural Research Center, Agricultural Research Service, U.S. Department of Agriculture for providing soil-composts and obtaining animal fecal samples, respectively. This research was partially supported by the Cooperative Agreement between the Experiment and Research Institute, National Agricultural Products Quality Management Service, Republic of Korea and Agricultural Research Service, USDA, USA.

Author Contributions: Hyunjeong Cho, Hoonsoo Lee, Alan M. Lefcourt, and Diane E. Chan conceived, designed, performed the experiments; Sungyoun Kim, Dongho Kim, and Moon S. Kim analyzed the data; Hyunjeong Cho wrote the paper and Soo Hyun Chung and Moon S. Kim contributed substantially to the reviewing and revising of the manuscript.

Conflicts of Interest: The authors declare no conflict of interest.

\section{References}

1. Centers for Disease Control and Prevention. Vital Signs: Incidence and Trends of Infection with Pathogens Transmitted Commonly Through Food-Foodborne Diseases Active Surveillance Network, 10 U.S. Sites, 1996-2010. Morb. Mortal. Wkly. Rep. 2011, 60, 749-755.

2. D'lima, C. Produce Related Outbreaks and illnesses 1996 to 2010_FDA Memorandum to the Record re Standards for the Growing, Harvesting, Packing, and Holding of Produce for Human Consumption. Available online: http://www.regulations.gov/document?D=FDA-2011-N-0921-18884 (accessed on 25 August 2016).

3. Doyle, M.P.; Erickson, M.C. Summer meeting 2007-The problems with fresh produce: An overview. J. Appl. Microbiol. 2008, 105, 317-330. [CrossRef] [PubMed]

4. Warriner, K.; Huber, A.; Namvar, A.; Fan, W.; Dunfield, K. Recent Advances in the Microbial Safety of Fresh Fruits and Vegetables. Adv. Food Nutr. Res. 2009, 57, 155-208. [PubMed] 
5. Centers for Disease Control and Prevention. CDC Estimates of Foodborne Illness in the United States CDC 2011 Estimates. Cent. Dis. Control Prev. 2011, 68, 3-4.

6. Islam, M.; Morgan, J.; Doyle, M.P.; Phatak, S.C.; Millner, P.; Jiang, X. Persistence of Salmonella enterica serovar typhimurium on lettuce and parsley and in soils on which they were grown in fields treated with contaminated manure composts or irrigation water. Foodborne Pathog. Dis. 2004, 1, 27-35. [CrossRef] [PubMed]

7. Buck, J.W.; Walcott, R.R.; Beuchat, L.R. Recent Trends in Microbiological Safety of Fruits and Vegetables. Plant Health Prog. 2003, 10. [CrossRef]

8. Doyle, M.E.; Archer, J.; Kaspar, C.W.; Weiss, R. Human Illness Caused by E. coli O157:H7 from Food and Non-Food Sources; Food Research Institute, University of Wisconsin: Madison, WI, USA, 2006.

9. Zaleski, K.J.; Josephson, K.L.; Gerba, C.P.; Pepper, I.L. Survival, Growth, and Regrowth of Enteric Indicator and Pathogenic Bacteria in Biosolids, Compost, Soil, and Land Applied Biosolids. J. Residuals Sci. Technol. 2005, 2, 49-63.

10. Stephens, T.P.; Loneragan, G.H.; Thompson, T.W.; Sridhara, A.; Branham, L.A.; Pitchiah, S.; Brashears, M.M. Distribution of Escherichia coli $\mathrm{O} 157$ and Salmonella on hide surfaces, the oral cavity, and in feces of feedlot cattle. J. Food Prot. 2007, 70, 1346-1349.

11. Mandrell, R.E. Enteric Human Pathogens Associated with Fresh Produce: Sources, Transport, and Ecology. In Microbial Safety of Fresh Produce; Wiley-Blackwell: Hoboken, NJ, USA, 2009; pp. 1-41.

12. Jay, M.T.; Cooley, M.; Carychao, D.; Wiscomb, G.W.; Sweitzer, R.A.; Crawford-Miksza, L.; Farrar, J.A.; Lau, D.K.; O'connell, J.; Millington, A.; et al. Escherichia coli O157:H7 in Feral Swine near Spinach Fields and Cattle, Central California Coast 1. Emerg. Infect. Dis. 2007, 13, 1908-1911. [CrossRef] [PubMed]

13. Reynnells, R.; Ingram, D.T.; Roberts, C.; Stonebraker, R.; Handy, E.T.; Felton, G.; Vinyard, B.T.; Millner, P.D.; Sharma, M. Comparison of U.S. Environmental Protection Agency and U.S. Composting Council Microbial Detection Methods in Finished Compost and Regrowth Potential of Salmonella spp. and Escherichia coli O157:H7 in Finished Compost. Foodborne Pathog. Dis. 2014, 11, 555-567. [CrossRef] [PubMed]

14. Teplitski, M.; George, A.; Hochmuth, G. Salmonella and Pathogenic E. coli in the Crop Production Environment: Potential Sources, Survival, Domestic and Wild Animals as Vectors of Human Pathogens Surveys of Microbiological Water Quality Source of Human Pathogens. Univ. Fla. IFAS Ext. 2012, SL375, 1-3.

15. Gorski, L.; Parker, C.T.; Liang, A.; Cooley, M.B.; Jay-Russell, M.T.; Gordus, A.G.; Atwill, E.R.; Mandrell, R.E. Prevalence, distribution, and diversity of Salmonella enterica in a major produce region of California. Appl. Environ. Microbiol. 2011, 77, 2734-2748. [CrossRef] [PubMed]

16. Wichuk, K.M.; McCartney, D. A review of the effectiveness of current time-temperature regulations on pathogen inactivation during composting. J. Environ. Eng. Sci. 2007, 6, 573-586. [CrossRef]

17. Department of Health \& Human Services. Standards for the Growing, Harvesting, Packing, and Holding of Produce for Human Consumption. Fed. Regist.; 2015. Available online: https:/ /www.gpo.gov/fdsys/pkg/ FR-2015-11-27/pdf/2015-28159.pdf (accessed on 25 August 2016).

18. Deak, T. Testing Methods in Food Microbiology. Food Qual. Stand. 2008, III, 23-45.

19. Zhao, X.; Lin, C.-W.; Wang, J.; Oh, D.H. Advances in rapid detection methods for foodborne pathogens. J. Microbiol. Biotechnol. 2014, 24, 297-312. [CrossRef] [PubMed]

20. Dale, L.M.; Thewis, A.; Boudry, C.; Rotar, I.; Dardenne, P.; Baeten, V.; Pierna, J.A.F. Hyperspectral Imaging Applications in Agriculture and Agro-Food Product Quality and Safety Control: A Review. Appl. Spectrosc. Rev. 2013, 48, 142-159. [CrossRef]

21. Gowen, A.A.; O’Donnell, C.P.; Cullen, P.J.; Downey, G.; Frias, J.M. Hyperspectral imaging-An emerging process analytical tool for food quality and safety control. Trends Food Sci. Technol. 2007, 18, 590-598. [CrossRef]

22. Park, B.; Windham, W.R.; Lawrence, K.C.; Smith, D.P. Contaminant Classification of Poultry Hyperspectral Imagery using a Spectral Angle Mapper Algorithm. Biosyst. Eng. 2007, 96, 323-333. [CrossRef]

23. Pu, Y.Y.; Feng, Y.Z.; Sun, D.W. Recent progress of hyperspectral imaging on quality and safety inspection of fruits and vegetables: A review. Compr. Rev. Food Sci. Food Saf. 2015, 14, 176-188. [CrossRef]

24. Wu, D.; Sun, D.-W. Advanced applications of hyperspectral imaging technology for food quality and safety analysis and assessment: A review-Part I: Fundamentals. Innov. Food Sci. Emerg. Technol. 2013, 19, 15-28. [CrossRef] 
25. Wu, D.; Sun, D.-W. Hyperspectral Imaging Technology: A Non-Destructive Tool for Food Quality and Safety Evaluation and Inspection. In Advances in Food Process Engineering Research and Applications; Springer US: New York, NY, USA, 2013; pp. 581-606.

26. Huang, H.; Liu, L.; Ngadi, M.O. Recent developments in hyperspectral imaging for assessment of food quality and safety. Sensors 2014, 14, 7248-7276. [CrossRef] [PubMed]

27. Kim, M.S.; Lefcourt, A.M.; Chen, Y.-R. Optimal fluorescence excitation and emission bands for detection of fecal contamination. J. Food Prot. 2003, 66, 1198-1207. [PubMed]

28. Kim, M.S.; Lefcourt, A.M.; Chao, K.; Chen, Y.R.; Kim, I.; Chan, D.E. Multispectral Detection of Fecal Contamination on Apples based on Hyperspectral Imagery: Part I. Application of Visible and Near-Infrared Refrectance Imaging. Trans. ASAE 2002, 45, 2027-2037.

29. Kim, M.S.; Lefcourt, A.M.; Chen, Y.R.; Kim, I.; Chan, D.E.; Chao, K. Multispectral Detection of Fecal Contamination on Apples based on Hyperspectral Imagery: Part II. Application of Hyperspectral Fluorescence Imaging. Trans. ASAE 2002, 45, 2039-2047.

30. Kim, M.S.; Lee, K.; Chao, K.; Lefcourt, A.M.; Jun, W.; Chan, D.E. Multispectral line-scan imaging system for simultaneous fluorescence and reflectance measurements of apples: Multitask apple inspection system. Sens. Instrum. Food Qual. Saf. 2008, 2, 123-129. [CrossRef]

31. Vargas, A.M.; Kim, M.S.; Tao, Y.; Lefcourt, A.M.; Chen, Y.R.; Luo, Y.; Song, Y.; Buchanan, R. Detection of fecal contamination on cantaloupes using hyperspectral fluorescence imagery. J. Food Sci. 2005, 70, E471-E476. [CrossRef]

32. Romaniello, R.; Peri, G.; Leone, A. Fluorescence hyper-spectral imaging to detecting faecal contamination on fresh tomatoes. J. Agric. Eng. 2016, 47, 7-11. [CrossRef]

33. Everard, C.D.; Kim, M.S.; Lee, H. A comparison of hyperspectral reflectance and fluorescence imaging techniques for detection of contaminants on spinach leaves. J. Food Eng. 2014, 143, 139-145. [CrossRef]

34. Kang, S.; Lee, K.; Son, J.; Kim, M.S. Detection of fecal contamination on leafy greens by hyperspectral imaging. Procedia Food Sci. 2011, 1, 953-959. [CrossRef]

35. Lee, H.; Everard, C.D.; Kang, S.; Cho, B.K.; Chao, K.; Chan, D.E.; Kim, M.S. Multispectral fluorescence imaging for detection of bovine faeces on Romaine lettuce and baby spinach leaves. Biosyst. Eng. 2014, 127, 125-134. [CrossRef]

36. Maxwell, K.; Johnson, G.N. Chlorophyll fluorescence-A practical guide. J. Exp. Bot. 2000, 51, $659-668$. [CrossRef] [PubMed]

37. Peterson, R.B.; Oja, V.; Laisk, A. Chlorophyll fluorescence at 680 and $730 \mathrm{~nm}$ and leaf photosynthesis. Photosynth. Res. 2001, 70, 185-196. [CrossRef] [PubMed]

38. Bernal, M.P.; Alburquerque, J.A.; Moral, R. Composting of animal manures and chemical criteria for compost maturity assessment. A review. Bioresour. Technol. 2009, 100, 5444-5453. [CrossRef] [PubMed]

39. Lannan, A.P.; Erich, M.S.; Ohno, T. Compost feedstock and maturity level affect soil response to amendment. Biol. Fertil. Soils 2013, 49, 273-285. [CrossRef]

40. Brost, R. Biosolids Management Handbook. Available online: https://www.epa.gov/sites/production/ files/documents/handbook1.pdf (accessed on 25 August 2016).

41. USC Council. Test methods for the examination of composting and compost. Rokonkoma, NY, USA, 2002. Available online: http://compostingcouncil.org/wp/wp-content/plugins/wp-pdfupload/pdf/34/ TMECC\%20Purpose,\%20Composting\%20Process.pdf (accessed on 15 August 2016).

(C) 2016 by the authors; licensee MDPI, Basel, Switzerland. This article is an open access article distributed under the terms and conditions of the Creative Commons Attribution (CC-BY) license (http://creativecommons.org/licenses/by/4.0/). 